\title{
The Use of Skin Fibroblast Cultures in the Detection of Respiratory Chain Defects in Patients with Lacticacidemia
}

\author{
BRIAN H. ROBINSON, D. MOIRA GLERUM, WENDY CHOW, ROUMYANA PETROVA- \\ BENEDICT, ROBERT LIGHTOWLERS, AND RODERICK CAPALDI \\ Department of Paediatrics and Biochemistry, University of Toronto [B.H.R., D.M.G., W.C., R.P.B.] and The \\ Research Institute, The Hospital for Sick Children, Toronto, Ontario, Canada [B.H.R., D.M.G., W.C., R.P.B.] \\ and Department of Molecular Biology, University of Oregon, Eugene, Oregon 97403 [R.L., R.C.]
}

\begin{abstract}
Cultured skin fibroblasts from patients with lacticacidemia were incubated with glucose for $1 \mathrm{~h}$ and the lactate and pyruvate production measured. Those patients with increased lactate to pyruvate ratios were further analyzed for the cause of the abnormal redox state. Two categories of patients are described. The first contains patients with either severe or partial cytochrome oxidase deficiency; this group can be broken down further into patients with Leigh's disease, Kearns-Sayre syndrome, and liver-specific cytochrome oxidase deficiency. In this group, the rise in lactate to pyruvate ratio roughly correlated with the severity of the defect. The second patient category had defects located in complex $I$ of the mitochondrial respiratory chain. This is easily demonstrated in the most severely affected patients with the fatal infantile form of the disease. Patients with severe defects in either complex I or cytochrome oxidase had complexes that were only partially assembled. Patients with mitochondrial encephalopathy with lactic acidosis and stroke-like episodes demonstrated only minor changes in redox state and in the behavior of the mitochondrial respiratory chain. (Pediatr Res 28: 549555,1990 )
\end{abstract}

\section{Abbreviations}

MELAS, mitochondrial encephalopathy with lactic acidosis and stroke-like episodes

The inborn errors of metabolism known to be primary causes of lacticacidemia include defects in pyruvate carboxylase (1), the pyruvate dehydrogenase complex (2), and the respiratory chain (3). Although the first two produce devastating results in early life in those affected, the majority of reported cases with respiratory chain defects have thus far been older children or adults $(4,5)$. These cases have often been diagnosed after the presentation of "mitochondrial myopathy" with abnormal mitochondrial appearance in muscle, either by light or electron microscopy.

Our approach has been somewhat different. Over the past 5 years, we have sought to identify patients with respiratory chain defects by examining the redox state of cultured skin fibroblasts. Although this has taught us that some well-recognized respiratory chain defects are not expressed in fibroblasts, such as fatal

Received December 14, 1989; accepted June 6, 1990.

Correspondence: Dr. Brian H. Robinson, Ph.D., Research Institute, The Hospital for Sick Children, 555 University Avenue, Toronto, Ontario, Canada M5G $1 \mathrm{X} 8$.

Supported by the Canadian Medical Research Council, the National Foundation, The March of Dimes, and the Beta Sigma Phi Sorority. infantile cytochrome oxidase deficiency, we have clearly identified a group of neonates and infants with lacticacidemia not previously well documented $(6,7)$.

\section{MATERIALS AND METHODS}

Skin fibroblast cultures. Human skin fibroblasts were grown from explants of forearm skin biopsy tissue (taken with informed parental consent). Culture medium was Eagle's $\alpha$-minimal essential medium supplemented with $10 \%$ FCS and extra glucose to bring the final medium glucose to $10.5 \mathrm{mM}$.

Determination of $L / P$ ratios. Confluent skin fibroblast cultures ( $1 \mathrm{mg}$ cell protein) were drained of culture fluid and the medium was replaced with $2 \mathrm{~mL}$ of Krebs phosphate buffer. The fibroblast cultures were incubated at $37^{\circ} \mathrm{C}$ for $1 \mathrm{~h}$ to deplete glycogen reserves; at this point the buffer was replaced by $1 \mathrm{~mL}$ Krebs phosphate buffer containing $1 \mathrm{mM}$ glucose. After $1 \mathrm{~h}, 0.1 \mathrm{~mL}$ 1.6 $\mathrm{M}$ perchloric acid was added and the cells were scraped from the dish with acidified buffer. After centrifugation to remove the pellet, the supernatant was assayed for lactate and pyruvate (8). The pellet was assayed for protein.

Determination of respiratory chain activities. Whole cell cytochrome oxidase was measured as described by Glerum et al. (9). Mitochondria were isolated from cultured skin fibroblasts and activities of the respiratory chain components were measured as follows: rotenone-sensitive NADH-cytochrome $\mathrm{c}$ reductase by the method of Moreadith et al. (10), cytochrome oxidase by the method of DiMauro et al. (11), and succinate-cytochrome c reductase by following the reduction of cytochrome $\mathrm{c}$ at $550 \mathrm{~nm}$ (12).

Northern and Western blotting. Western blotting was carried out as described previously using mitochondria isolated from fibroblasts $(1,9)$. Northern blotting was carried out using total mRNA prepared from fibroblasts, as described previously (3), and electrophoresed in $1 \%$ agarose containing formaldehyde. The mRNA was transferred to a Hybond support (Amersham, Arlington Heights, IL) and probed with ${ }^{32} \mathrm{P}$-labeled cDNA obtained by random priming of cDNA for subunit II or IV of cytochrome oxidase. The cDNA for cytochrome oxidase subunit IV was a gift from Eric Schon, Columbia University, New York.

\section{RESULTS AND DISCUSSION}

Approach to diagnosis of respiratory chain defects. When cultured skin fibroblasts are grown in Eagle's $\alpha$-minimal essential medium bicarbonate buffered medium with a $5 \% \mathrm{CO}_{2} 95 \%$ air atmosphere, they initially derive much of their energy for growth from converting glucose to pyruvic and lactic acids. Within a few days of subculture in medium containing $5.5 \mathrm{mM}$ glucose, the glucose disappears from the culture medium with $84 \%$ of it 
reappearing in the medium as lactate and pyruvate (13). If culture is continued without further glucose supplementation, the lactate and pyruvate are then metabolized oxidatively to provide energy (13). This reliance of cultured fibroblasts on glycolysis does not make them an ideal system for studying oxidative metabolic defects.

However, the ratio of accumulated lactic to pyruvic acid can give important information about the redox state of the cell and thus reveal problems in respiratory chain function. The lactate dehydrogenase reaction is at equilibrium in normal fibroblasts such that

$$
\frac{\text { lactate }}{\text { pyruvate }} \times \mathrm{K}_{\mathrm{LDH}}=\frac{\mathrm{NADH}}{\mathrm{NAD}^{+}}
$$

where $\mathrm{K}_{\mathrm{LDH}}$ is the equilibrium constant of the lactate dehydrogenase. Because the $\mathrm{L} / \mathrm{P}$ ratio observed in fibroblast cultures after incubation with glucose is approximately $25: 1$, it follows that 25 $\times 1.11 \times 10^{-4}=\mathrm{NADH} / \mathrm{NAD}$; therefore, $\mathrm{NAD} / \mathrm{NADH}=360$.

This value for $\mathrm{NAD} / \mathrm{NADH}$ of 360 is similar to that seen in other mammalian cells, and reflects the redox state in the cytosolic compartment, a state maintained in an equilibrium with pyridine nucleotide redox state of the mitochondrial compartment. These couples are linked by the glutamate/aspartate shuttle system (Fig. 1;14), such that the mitochondrial NAD/NADH ratio favors the reduced form, being between 10:1 and 30:1 (15). This difference in cytosolic and mitochondrial pyridine nucleotide redox states is maintained by the electrogenic expulsion of aspartate from the mitochondrial to the cytosolic compartment (16). In turn, the mitochondrial NAD/mitochondrial NADH ratio is in equilibrium with the oxidized-reduced cytochrome $\mathrm{c}$ couple as modulated by the ratio ATP/(ADP) (inorganic phosphate) in the cell $(17,18)$.

Measurements of cellular $\mathrm{L} / \mathrm{P}$ ratio are summarized in Figure 2. The cells were incubated in a buffer containing glucose for 1 $\mathrm{h}$, as described earlier, and the lactate and pyruvate measured a number of times for each cell line. Control cells produce about

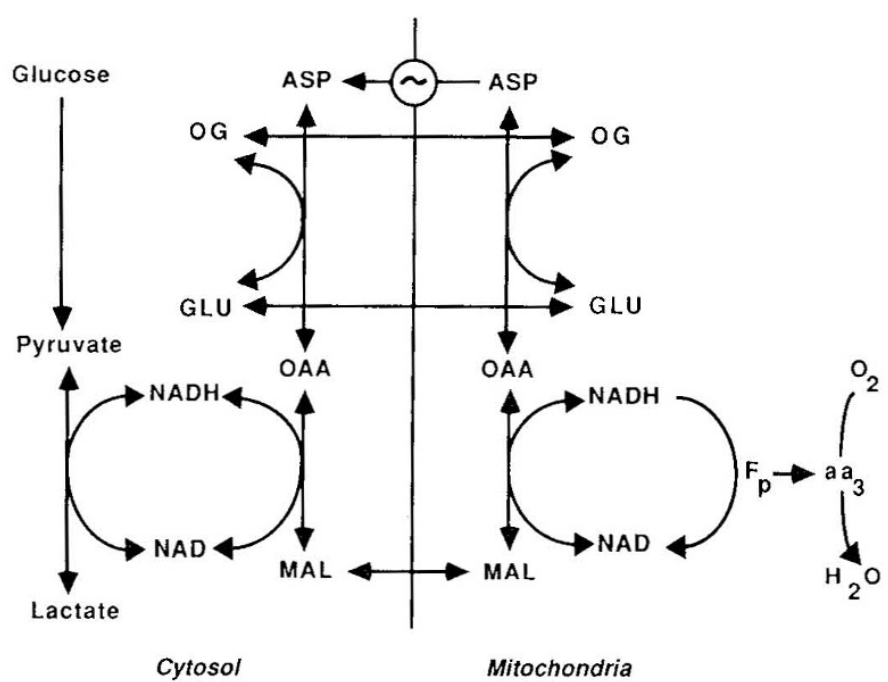

Fig. 1. The linking of the $\mathrm{L} / \mathrm{P}$ equilibrium to the intramitochondrial redox state. The equilibrium between pyruvate and lactate at lactate dehydrogenase and between malate and oxaloacetate at malate dehydrogenase is linked through the NAD/NADH redox couple in the cytosol. The intra- and extramitochondrial aspartate aminotransferases and the malate, oxoglutarate, glutamate, and aspartate transporting systems in the mitochondrial membrane permit the metabolites of the intra- and extramitochondrial malate dehydrogenases to communicate. The intramitochondrial and extramitochondrial NAD/NADH couples are therefore in communication. However, the cytosolic couple remains much more oxidized because of electrogenic expulsion of aspartate from the mitochondrial compartment.

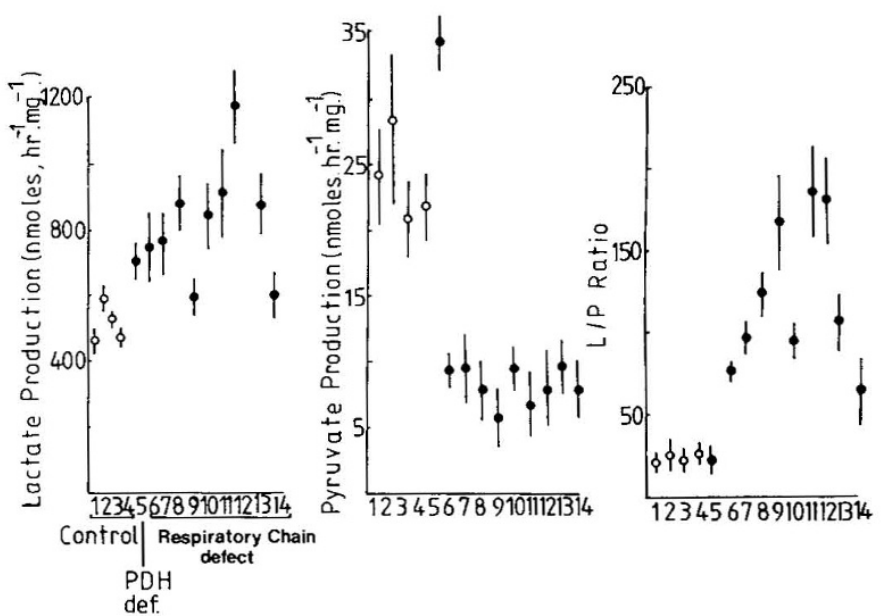

Fig. 2. Lactate and pyruvate production in cultured skin fibroblasts. Confluent skin fibroblast cultures were incubated with Krebs phosphate buffer for $1 \mathrm{~h}$, then with Krebs phosphate buffer plus glucose as described in Materials and Methods. After $1 \mathrm{~h}$, the reaction was stopped by the addition of perchloric acid, and lactate and pyruvate were measured. The lactate measured and the pyruvate measured for each cell line is shown followed by the calculated $\mathrm{L} / \mathrm{P}$ ratio. Fibroblast cell lines were as follows: 1, 2, 3, and 4 were control cell lines 1228, 1685, 1206, and 806; 5 was pyruvate dehydrogenase-deficient cell line 1373; and 6-14 were cell lines later shown to have respiratory chain defects, cell lines 1630 , $1680,1909,1489,2288,2020,1895,2207$, and 2233. Values are expressed as the mean of at least five determinations \pm SEM.

$500 \mathrm{nmol}$ of lactate and about $25 \mathrm{nmol}$ of pyruvate, giving an $\mathrm{L} / \mathrm{P}$ ratio between $20: 1$ and $30: 1$. When the pyruvate dehydrogenase complex is deficient, higher rates of lactate and pyruvate production are seen, with an $\mathrm{L} / \mathrm{P}$ ratio that is normal or low (19). When the mitochondrial respiratory chain is defective, the lactate output is increased, whereas the pyruvate output is decreased, giving an elevated $\mathrm{L} / \mathrm{P}$ ratio $(6,7,9)$. Those patients with elevated $\mathrm{L} / \mathrm{P}$ ratios can be divided into two basic groups, those with defects in the cytochrome oxidase complex (complex IV of the respiratory chain) and those with defects in NADHcoenzymeQ oxidoreductase (complex I of the respiratory chain).

Defects in cytochrome oxidase. In the cytochrome oxidase deficiencies, there was a surprisingly good correlation between the severity of the defect and the magnitude of the $\mathrm{L} / \mathrm{P}$ ratio. Figure 3 shows that an increasing L/P ratio is associated with decreasing residual whole cell cytochrome oxidase activity. Twelve patients with Leigh's disease (subacute necrotizing encephalomyelopathy) had low $(<25 \%)$ cytochrome oxidase activities and L/P ratios of greater than 100:1 in skin fibroblasts. Another cluster of patients with partial defects of cytochrome oxidase had varied clinical presentations. One patient had Kearns-Sayre syndrome, two had hepatomegaly and severe liver cytochrome oxidase deficiency, and five had Leigh's disease. One patient died at 3 mo with a severe ventricular cardiomyopathy.

In the patients with partial cytochrome oxidase deficiency and Leigh's disease, the enzyme had abnormal kinetics with respect to both oxidized and reduced cytochrome c (Fig. 4). There appeared to be inhibition by both high concentrations of the substrate, reduced cytochrome $\mathrm{c}$, and the product, oxidized cytochrome $\mathrm{c}(7)$, that were not seen in cytochrome c oxidase from normal fibroblasts. In the partial defect seen in KearnsSayre syndrome, we analyzed mitochondrial DNA and found no detectable deletions in these cells, despite the presence of cytochrome oxidase deficiency. Isolated liver cytochrome oxidase deficiency suggests that a defect is present in a subunit with a liver-specific isoform, such as subunits VII, IX, and ASA (the $N$ terminal amino acids of cytochrome oxidase subunit alanineserine-alanine are used to designate the identity of this subunit).

We have examined extensively the synthesis of cytochrome 
oxidase in the deficient fibroblast cultures $(9,20)$. The majority of those with severe cytochrome oxidase deficiency did not assemble the complex. Those with partial defects either underwent partial assembly or full assembly of the complex (Fig. 5),

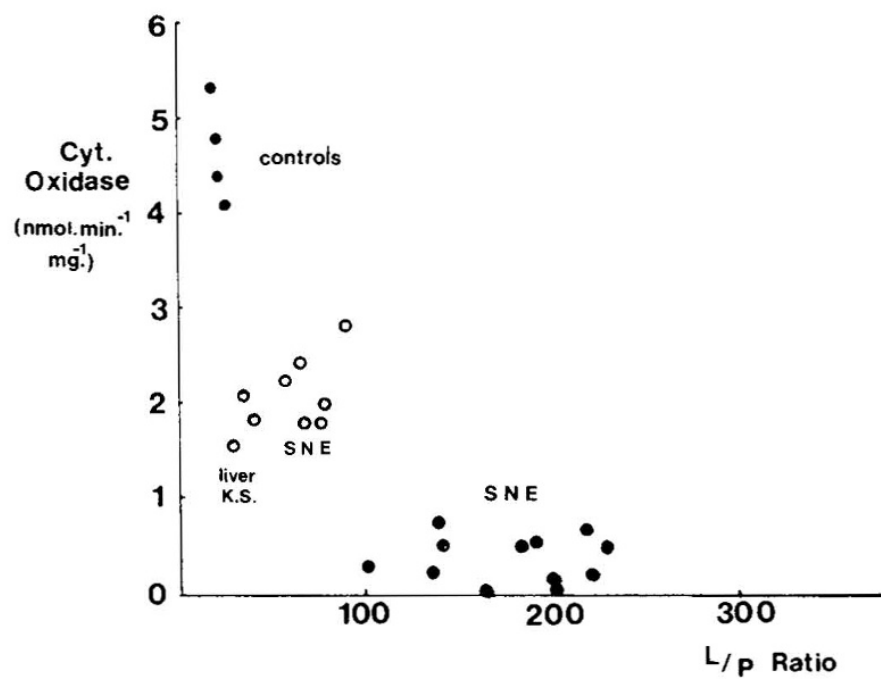

Fig. 3. The correlation of cytochrome oxidase activity with $\mathrm{L} / \mathrm{P}$ ratio. The activity of whole cell fibroblast cytochrome oxidase is plotted against the $\mathrm{L} / \mathrm{P}$ ratio determined by incubation with glucose. Each point represents one cell line. $\bullet$, control cell lines; $\bigcirc$, patients with various forms of cytochrome oxidase deficiency.

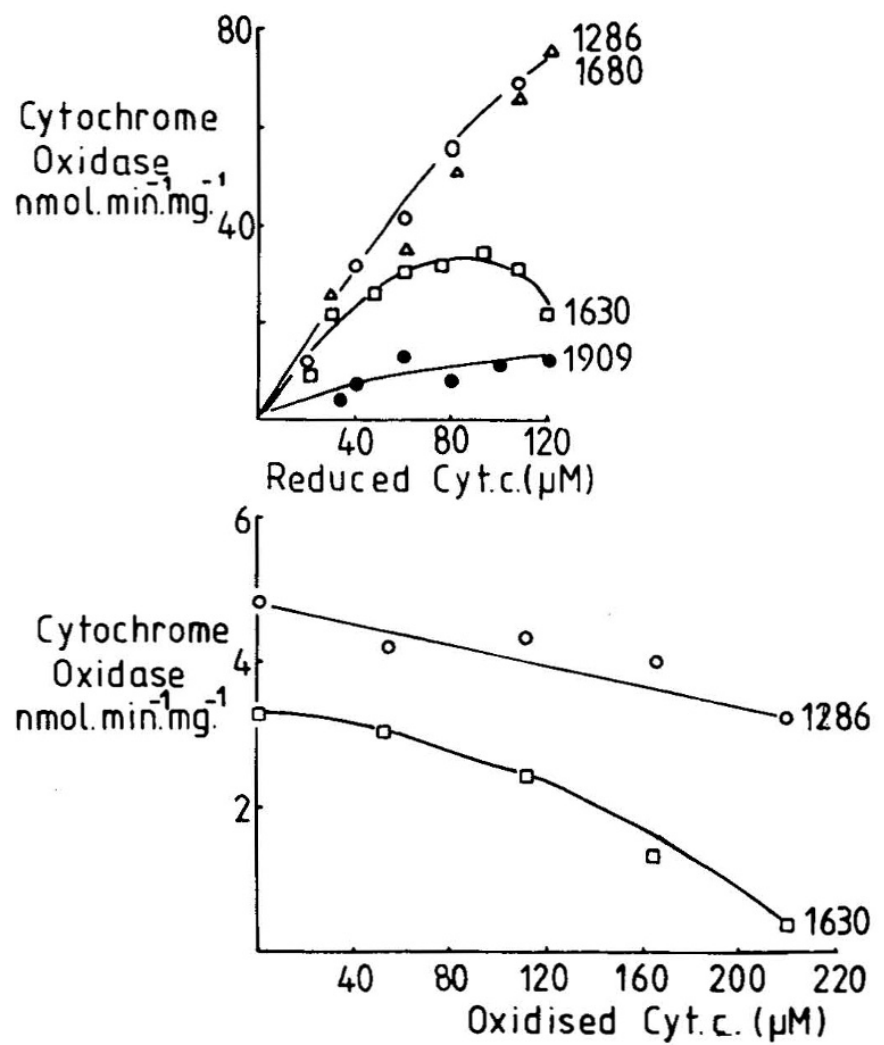

Fig. 4. The dependence of cytochrome oxidase activity on the concentration of reduced cytochrome c (top) and oxidized cytochrome c (bottom) in a patient with partial cytochrome oxidase deficiency and Leigh's disease. Determinations were carried out using a sonicated mitochondrial preparation from either the control or patient's cells; $\Delta$, control cell line 1286; $\bigcirc$, complex I deficient cell line $1680 ; \square$, partially deficient cell line 1630; half of the figure, whole cell cytochrome oxidase was measured as a function of oxidized cytochrome $\mathrm{c}$ concentration at a substrate concentration of $80 \mu \mathrm{m}$ reduced cytochrome c.
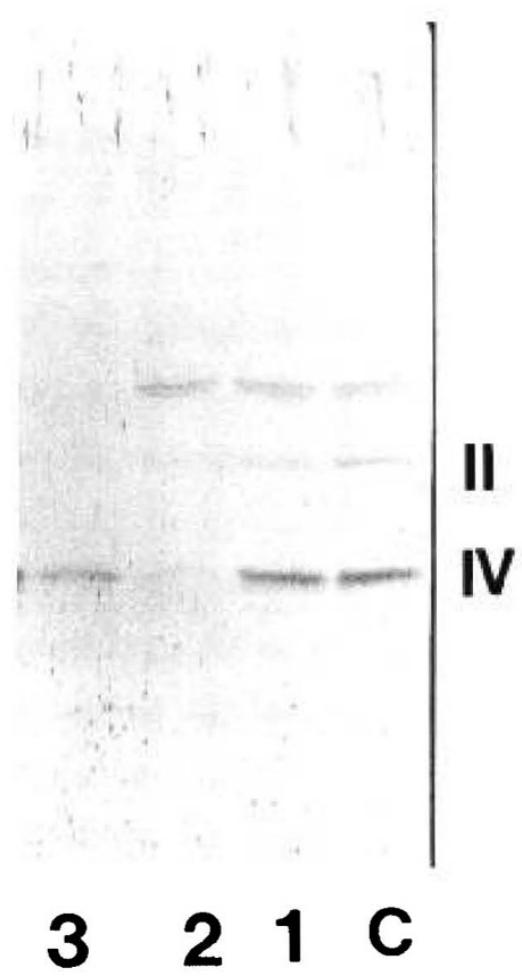

Fig. 5. Western blotting of fibroblast mitochondrial extracts with anticytochrome oxidase subunit antisera. The blot was performed as described in Materials and Methods, blotting with antiserum for subunit II and IV of cytochrome oxidase. The mitochondrial extracts were electrophoresed before blotting from; lane $C$, control cell line 1685; lane 1 , partially deficient cell line 1630; lane 2 , severely deficient cell line 2161 ; and lane 3 , severely deficient cell line 1909 .

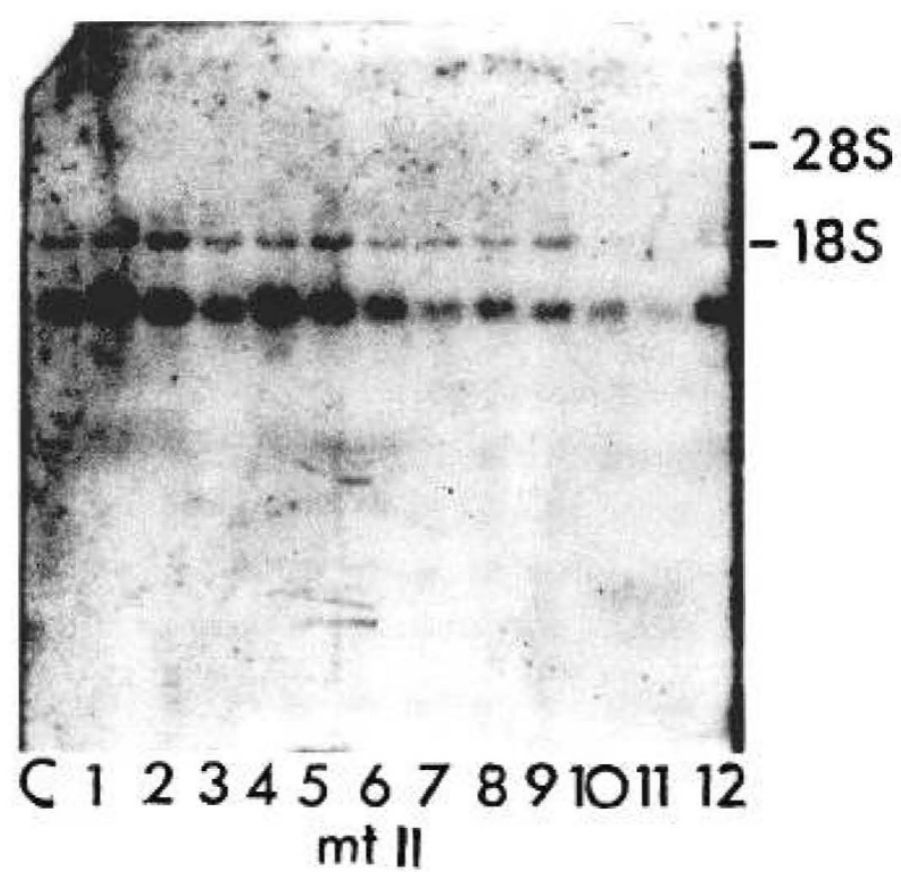

Fig. 6. Northern blotting of total RNA preparation from cytochrome oxidase-deficient fibroblasts. Total RNA ( $20 \mu \mathrm{g}$ per cell line) was electrophoresed on a $2.2 \mathrm{M}$ formaldehyde/ $1 \%$ agarose gel and transferred to a Hybond support membrane. This blot was then probed with a ${ }^{32} \mathrm{P}$-labeled cDNA probe for subunit II of cytochrome oxidase. Lane $C$ is control cell line 1206; lanes $1,5,8,9$ and 12 , severely defícient cell lines 1489,2161 , 2417,2435 , and 2612; and lanes 2, 3, 4, 6, 7, 10 and 11 , partially deficient cell lines 1630, 1947, 2130, 2233, 2288, 2440, and 2576. 
as shown by Western blotting with antibodies specific for subunit II and IV of cytochrome oxidase. On the other hand, immunoprecipitation of subunits using antibody against individual components or antibody against the whole complex showed that, even in the fibroblast cultures with nonassembly, as judged by Western blotting, newly synthesized ${ }^{35}$ S-labeled subunit IV can easily be demonstrated. This was confirmed by Northern blotting experiments in which the mRNA for subunits II (mitochondrial encoded) and IV (nuclear encoded) were present in both partial and nonassembling cytochrome oxidase-deficient fibroblasts (Figs. 6 and 7).

Spectrum of cytochrome oxidase deficiency. How then can we relate these fibroblast observations to the accumulated knowledge of cytochrome oxidase deficiency? Leigh's disease appears to be the major presentation for cytochrome oxidase deficiency. This deficiency has been present in all tissues tested (21), and has been extensively reported (22). Although the majority of KearnsSayre syndrome cases carry mitochondrial DNA deletions (23), they do not exhibit cytochrome oxidase deficiency in fibroblasts, despite the fact that they do so in muscle. The case we report here is an exception. Although liver-specific cytochrome oxidase deficiency is also rare, we have detected it here in cultured skin fibroblasts $(24,25)$. We have investigated skin fibroblasts from several cases of fatal infantile cytochrome oxidase deficiency (26). There is neither a raised $\mathrm{L} / \mathrm{P}$ ratio nor a decrease in cytochrome oxidase activity detectable in these cells.

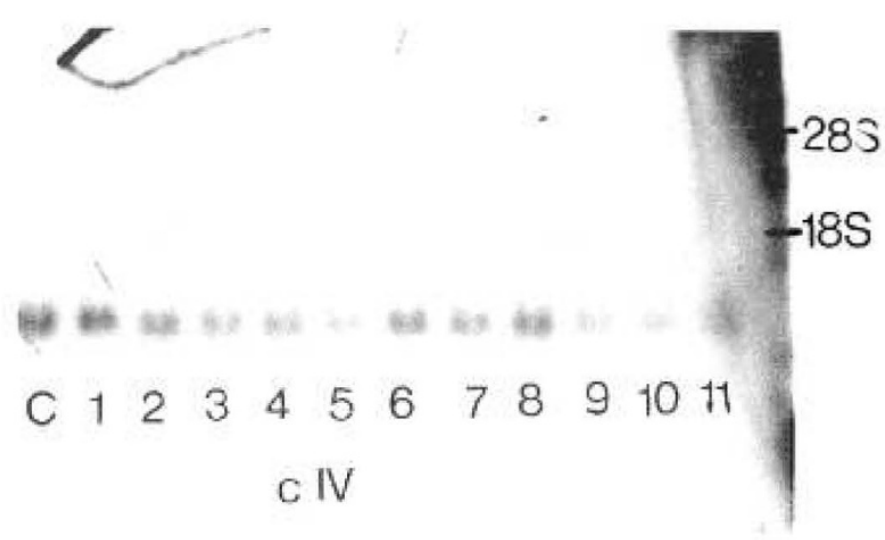

Fig. 7. Northern blotting of total RNA from cultured skin fibroblasts with cytochrome oxidase deficiency for subunit IV. Blotting was carried out as described for Figure 6, except that a cDNA probe for cytochrome oxidase subunit IV was used. Lane $C$ is control cell line 1206; lanes 2, $3,6,7,9$ and 11 , severely deficient cell lines 2161, 2417, 2434, 2550, and 2612; and lanes 2, 4, 5,8, and 10, partially deficient cell lines 2130 , $2233,2288,2446$, and 2576.
Defects in complex I. When a cultured fibroblast cell line demonstrates an altered redox state by virtue of an increased $\mathrm{L} / \mathrm{P}$ ratio but no cytochrome oxidase defect, further analysis is necessary. Initially, we measure whole cell succinate-cytochrome c reductase; we have never found this activity to be deficient in skin fibroblasts. This then means that any remaining cell line with increased $\mathrm{L} / \mathrm{P}$ ratio has a defect in either complex I, complex $\mathrm{V}$ (the oligomycin-sensitive ATPase) or the adenine nucleotide transporter. To date, most patient cell lines falling in this category have complex I defects, although this is sometimes difficult to demonstrate.

To illustrate this problem, we will examine the case of Moreadith et al. (10). This patient presented on the 1st day of life with respiratory distress and hypoglycemia. He was hypotonic, fed poorly, had poor respiratory effort, and was intubated from 3 wk of age until his death at 16 wk. The serum lactic acid increased from $5 \mathrm{mM}$ in the neonatal period to greater than 20 $\mathrm{mM}$ toward the end of his life. Detailed studies performed on mitochondria isolated from various tissues at the time of his death showed a complex I defect that varied in severity among the tissues, residual activities being $2 \%$ in skeletal muscle, $11 \%$ in liver, $16 \%$ in heart, and $33 \%$ in kidney. Our studies of his skin fibroblast mitochondria showed that complex I activity in fibroblasts was normal, as was the rest of the respiratory chain (Table 1). However, the L/P ratio was elevated in fibroblasts, indicating that the defect was present, although in an occult form. We then checked the rate of ATP synthesis in isolated mitochondria from various substrates and found it normal both with NAD-linked substrates and with succinate. Thus, a complex I defect can alter the redox state without altering either the measured enzyme activity or the function of the complex in oxidative phosphorylation. This makes it difficult to diagnose some complex I defects definitively in fibroblasts, although we have demonstrated several to have deficient enzyme activity.

Spectrum of complex I deficiency. We examined the clinical histories of 25 patients with lacticacidemia in whose cells we had demonstrated an increased $\mathrm{L} / \mathrm{P}$ ratio (Fig. 8 ). The patients fell into roughly four categories. The first group had lacticacidemia from birth associated with acidosis. Death always occurred in the first 4 mo of life and all had hypotonia and anorexia. Three had a ventricular cardiomyopathy and two showed mitochondrial hypertrophy in muscle. There were two groups with the diagnosis of Leigh's disease. The first had unusually early onset and rapid progression; death occurred at $10 \mathrm{wk}$ in one case (Table 2). Three of these children had a ventricular cardiomyopathy. The other group had a more typical Leigh's disease progressive neurodegeneration; all initially progressed reasonably well, although most presented at 1 y of age because of stalled development. They, like the other Leigh's disease group, had mild lacticacidemia, with values rarely above $5 \mathrm{mM}$. Another

Table 1. Expression of complex I deficiency in cultured skin fibroblast*

\begin{tabular}{|c|c|c|c|}
\hline & \multicolumn{3}{|c|}{$\begin{array}{l}\text { NADH-cyt c reductase (rotenone sensitive) } \\
(\mathrm{nmol} / \mathrm{min} / \mathrm{mg} \text { protein })\end{array}$} \\
\hline & Patient & Control & $\%$ \\
\hline Heart $†$ & 56 & 347 & 16 \\
\hline Kidneyt & 35 & 107 & 33 \\
\hline Liver & 15 & 131 & 11 \\
\hline Skeletal muscle $\dagger$ & 5 & 206 & 2 \\
\hline Fibroblasts & $68 \pm 21(4)$ & $53 \pm 7(7)$ & 128 \\
\hline Lactate/pyruvate ratio & $88 \pm 11(6)$ & $26.9 \pm 1.6(11)$ & 327 \\
\hline \multicolumn{4}{|c|}{ Rate of ATP synthesis (isolated fibroblast mitchondria) } \\
\hline Pyruvate $5^{\prime} \mathrm{mM} / \mathrm{L}$ malate $1 \mathrm{mM}$ & $1117 \pm 36(3)$ & $746 \pm 68(4)$ & 149 \\
\hline Isocitrate $1 \mathrm{mM} / \mathrm{L}$ malate $1 \mathrm{mM}$ & $1577 \pm 155(3)$ & $1043 \pm 113(4)$ & 140 \\
\hline Succinate $5 \mathrm{mM}$ /antimycin $1 \mu \mathrm{M}$ & $1176 \pm 69(3)$ & $1063 \pm 102(5)$ & 111 \\
\hline
\end{tabular}

* Respiratory chain activities and lactate to pyruvate ratio in skin fibroblast cultures were determined as described in Materials and Methods. Rate of ATP synthesis was determined as described by Robinson et al. (3). Number of determinations in parentheses.

$\uparrow$ Values taken from Moreadith et al. (10). 
group demonstrated spastic quadriplegia from the neonatal period onward. These patients had moderate acidosis, with blood lactate levels in the range of 5-7 mM. Two of these patients had optic atrophy and two had translucencies visible in the basal ganglia on CT scanning.

Are these groups, as classified by clinical presentation, that much different from each other? Two pieces of information suggest strongly that there is overlap, if not contiguity, between these groups. First, one of the patients who presented with spastic quadriplegia had a sibling who, after a slow neurodegenerative course, died at 19 y of age with the pathology of Leigh's disease. Second, two cases of fatal neonatal lacticacidemia had documented postmortem pathology with degenerative changes in the

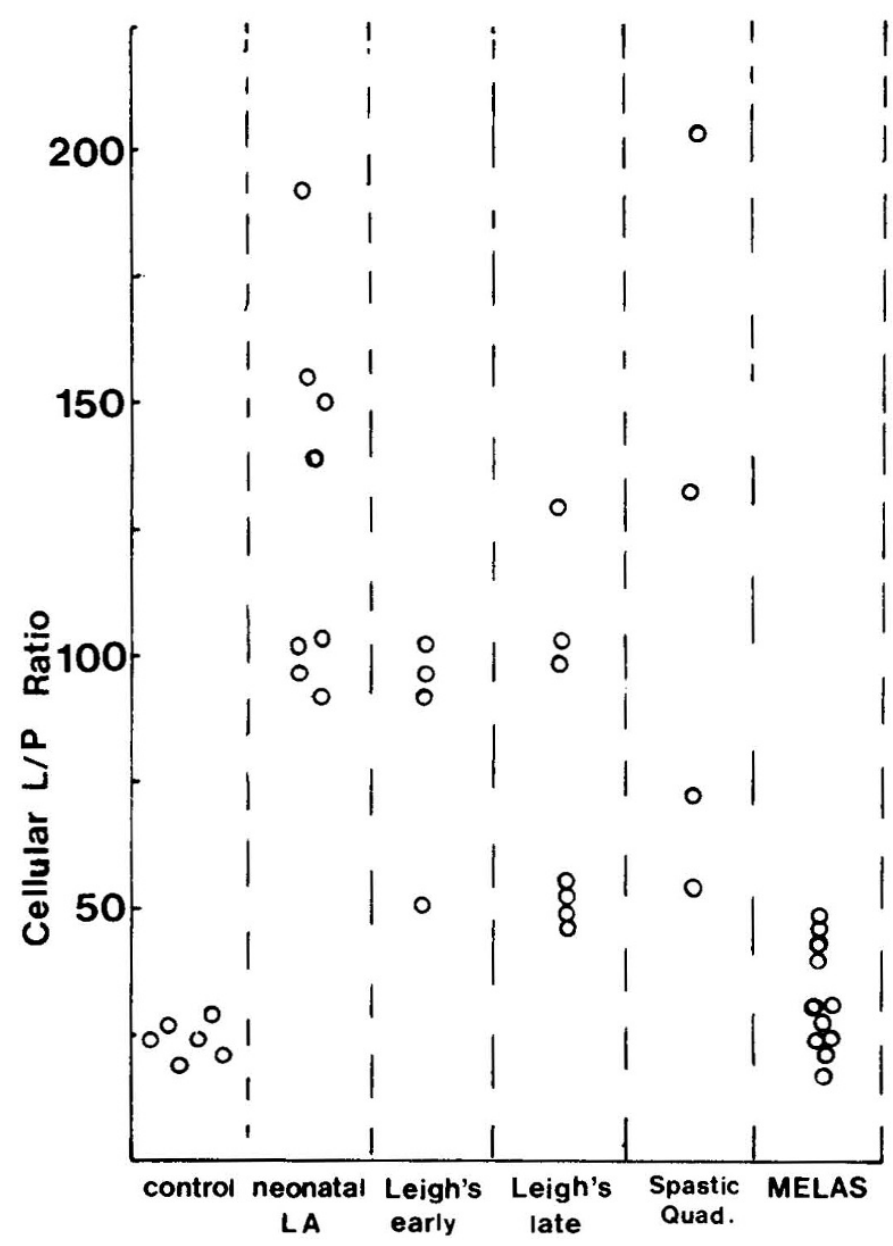

Fig. 8. Correlation of the $\mathrm{L} / \mathrm{P}$ ratio in cultured cells with clinical presentation in patients with normal fibroblasts cytochrome oxidase activity. The patients divide into four clinical groups: those who presented in the neonatal period with lacticacidosis, those who presented early with Leigh's disease, those with a later presentation for Leigh's disease, and those with spastic quadriplegia. L/P ratio was determined for fibroblast cultures as described in Materials and Methods. brainstem, spinal cord, basal ganglia, thalamus, and cerebellum, also overlapping with the early Leigh's disease group. However, other cases in the fatal neonatal group had only a spongiform encephalopathy at post-mortem. Thus, our classification may have to be reevaluated as further information about the nature of these defects becomes available. An interesting case reported by Hoppell et al. (27), like the report of Moreadith et al. (10), also documents complex I deficiency in a baby who presented with lactic acidosis, biventricular cardiomyopathy, anorexia, and hypotonia. This baby survived for 2 mo but showed spongiform changes in the cortex, putamen, globus pallidus, and hypothalamus. This patient, like most patients identified in our neonatal group, had an increased blood L/P ratio.

We have completed analysis of the respiratory chain activities in some members of this group (Table 3). The fatal infantile group seemed to have the most deficient activities, with the one exception shown earlier having normal activity. The one spastic quadriplegia patient also had quite deficient activity, whereas a case with late onset Leigh's disease had only mild deficiency. The isolated mitochondria from some of these cell lines were subjected to Western blotting using an anti-complex I antibody. The only consistent abnormalities in many severely affected fatal infantile (neonatal presentation) patients were very decreased amounts or absence of a number of proteins, including the 75 , $39,24,20$, and $13 \mathrm{kD}$ proteins (Fig. 9).

Table 3. Fibroblast respiratory chain activity*

\begin{tabular}{|c|c|c|}
\hline & $\begin{array}{c}(\mathrm{I}+\mathrm{III}) \\
\text { NADH-Cyt c reductase }\end{array}$ & $\mathrm{L} / \mathrm{P}$ ratio \\
\hline \multicolumn{3}{|c|}{ Fatal infantile } \\
\hline 1680 & $7.6 \pm 1.6(4) \dagger$ & $99 \pm 15(1) \dagger$ \\
\hline 1895 & $10.0 \pm 2.3(5) \dagger$ & $169 \pm 68(4) \dagger$ \\
\hline 2020 & $14.6 \pm 2.1(6) \dagger$ & $182 \pm 45(7) \dagger$ \\
\hline 2038 & $11.6 \pm 4.7(3) \dagger$ & $107 \pm 21(4) \dagger$ \\
\hline 1581 & $2.8 \pm 1.4(2) \dagger$ & $142 \pm 40(4) \dagger$ \\
\hline 2649 & $23.8 \pm 8.4(2) \dagger$ & $151 \pm 42(6) \dagger$ \\
\hline 2224 & $67.8 \pm 21(4)$ & $88 \pm 11(6) \dagger$ \\
\hline \multicolumn{3}{|c|}{ Spastic quadriplegia } \\
\hline 2212 & $16.3 \pm 4.8(4) \dagger$ & $131 \pm 22(5) \dagger$ \\
\hline \multicolumn{3}{|c|}{$\begin{array}{l}\text { Leigh's disease } \\
\text { (early onset) }\end{array}$} \\
\hline 2574 & $12.4 \pm 1.2(2) \dagger$ & $102 \pm 9(6) \dagger$ \\
\hline \multicolumn{3}{|c|}{$\begin{array}{l}\text { Leigh's disease } \\
\text { (late onset) }\end{array}$} \\
\hline 2249 & $32.3 \pm 3.5(3) \dagger$ & $57 \pm 8(5) \dagger$ \\
\hline \multicolumn{3}{|l|}{ Controls } \\
\hline 1286 & $53.4 \pm 6.8(7)$ & $23.4 \pm 2.5(8)$ \\
\hline 1685 & $52.7 \pm 7.9(6)$ & $26.9 \pm 1.6(11)$ \\
\hline \multicolumn{3}{|l|}{ MELAS } \\
\hline 2611 & $36.8 \pm 9.4(3)$ & $31.9 \pm 3.4(6)$ \\
\hline
\end{tabular}

* NADH cytochrome reductase (rotenone sensitive) was measured in fibroblast mitochondria as described previously (3). L/P ratio in fibroblasts after incubation with glucose was determined as in Materials and Methods. Values are given as mean \pm SEM.

$\dagger p<0.01$ with respect to controls.

Table 2. Clinical presentation of patients with high fibroblasts $L / P$ ratio (putative complex I deficiency)

\begin{tabular}{lcccc}
\hline & Fatal infantile & Moderate spastic quad & Leigh's (early) & Leigh's (late) \\
\hline$n$ & 8 & 4 & 4 & 8 \\
L/P ratio & $124 \pm 13$ & $119 \pm 34$ & $84 \pm 10$ & $75 \pm 14$ \\
Outcome & All died before 4 mo age & Two died before $4 \mathrm{y}$ & One died at 10 wk & All alive \\
Degree of acidosis & Severe & Moderate & Mild & Mild \\
Associated symptoms & Hypotonia, anorexia & $\begin{array}{l}\text { Spastic quadriplegia, pyschomotor } \\
\text { retardation }\end{array}$ & $\begin{array}{c}\text { Nystagmus, psychomotor } \\
\text { retardation }\end{array}$ & $\begin{array}{c}\text { 2 Hypertonic, 6 Hypotonic, } \\
\text { psychomotor retardation }\end{array}$ \\
Cardiomyopathy $(n)$ & 3 & 1 & 3 & 0 \\
Basal ganglia disease & 2 & 2 & 2 & 4 \\
CT $(n)$ & & & & \\
\hline
\end{tabular}




\section{$M \quad L L L \& \quad C N$}

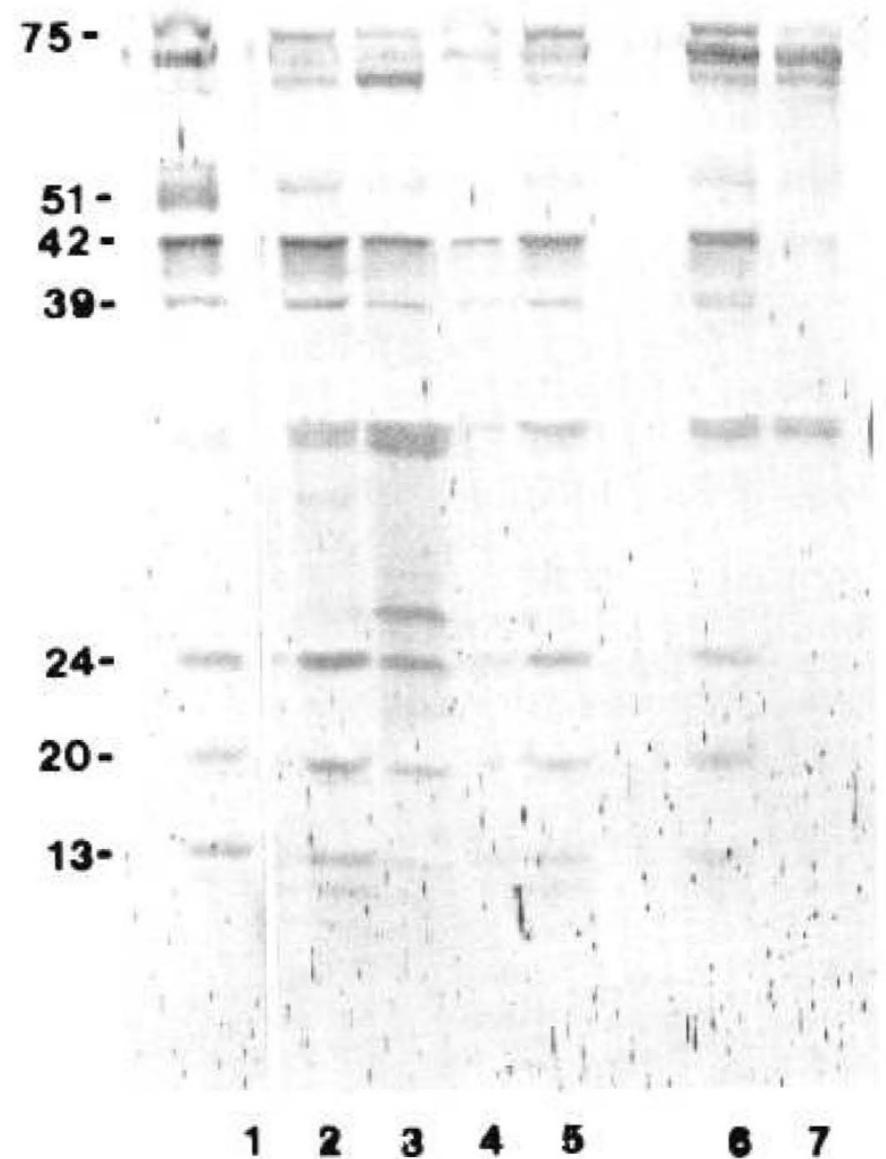

Fig. 9. Western blotting of cultured skin fibroblast mitochondrial protein with anti-complex I antibody. Mitochondria (100 $\mu \mathrm{g}$ protein) were isolated from skin fibroblast cultures of patients with putative complex I deficiency and the proteins run out on a $10 \%$ polyacrylamide gel. This gel was electroblotted onto a Hybond support matrix and blotted with anti-complex I antibody. Immunoreactive proteins were visualized with a biotinylated IgG-streptavidin peroxidase system (BioRad Laboratories, Mississauga, Ontario). Lane 1, human muscle mitochondria (control) $(M)$. Lanes 2, 3, and 4, patients with Leigh's disease $(L)$ (lane 4 has $50 \mu \mathrm{g}$ protein instead of $100 \mu \mathrm{g}$ protein). Lane 5 , patient with spastic quadriplegia. Lane 6, control cell line. Lane 7, patient with the neonatal lactic acidosis (fatal infantile).

The fibroblast complex I proteins identified on the blot were almost identical to those seen in muscle mitochondria. Thus, the situation is analogous to severe complex IV deficiency, where many of the components of the complex fail to assemble, resulting in low activity.

Is respiratory chain defect seen in muscle biopsies from $M E$ LAS patients expressed in fibroblasts? Patients with MELAS (28) have values for the $\mathrm{L} / \mathrm{P}$ ratio either in or just above the normal range (Fig. 8). Decreased activity of complex $I$ is the most common defect in muscles of MELAS patients, accompanied variably by decreased activity of cytochrome oxidase $(29,30)$. We investigated two cases of MELAS by Western blotting and found that the fibroblast mitochondrial complex I was indistinguishable from that in controls. However, complex I in muscle mitochondria had several missing subunits $(29,30)$. The activity of complex I in fibroblasts was insignificantly lower than that in controls in the one MELAS patient cell line tested (Table 3).
Thus, although the MELAS complex I defect may be at least partially expressed in fibroblasts, the level of expression is not the same as that seen in muscle. This would be compatible with a mitochondrial DNA-encoded defect in which heteroplasmy could account for familial and tissue differences $(31,32)$.

\section{REFERENCES}

1. Robinson BH, Oei J, Sherwood WG, Applegarth D, Wong L, Haworth J, Goodyer P, Casey R, Zaleski LA 1984 The molecular basis for the two different clinical presentations of classical pyruvate carboxylase deficiency. Am J Hum Genet 36:283-294

2. Robinson BH, MacMillan H, Petrova-Benedict R, Sherwood WG 1987 Variable clinical presentation in patients with deficiency of the pyruvate dehydrogenase complex. A review of 30 cases with a defect in the $\mathrm{E}_{1}$ component of the complex. J Pediatr 111:525-533

3. Robinson BH, Ward J, Goodyer P, Baudet A 1986 Respiratory chain defects in the mitochondria of cultured skin fibroblasts from three patients with lacticacidemia. J Clin Invest 77:1422-1427

4. DiMauro S, Bonilla E, Zeviani M, Nakagawa M, DeVivo DC 1985 Mitochondrial Myopathies. Ann Neurol 17:521-538

5. Sengers RCA, Stadhouders AM, Trijbels JMF 1984 Mitochondrial myopathies. Clinical, morphological and biochemical aspects. Eur J Pediatr 141:192-204

6. Robinson BH, De Meirleir L, Glerum M, Sherwood G, Becker L 1987 Clinical presentation of patients with mitochondrial respiratory chain defects in NADH Coenzyme Q reductase and cytochrome oxidase: clues to the pathogenesis of Leigh Disease. J Pediatr 110:216-222

7. Glerum M, Robinson BH, Spratt C, Wilson J, Patrick D 1987 Abnormal kinetic behaviour of cytochrome oxidase in a case of Leigh's disease. Am J Hum Genet 41:594-503

8. Robinson BH, MacKay N, Goodyer P, Lancaster G 1985 Defective intramitochondrial NADH oxidation in skin fibroblasts from an infant with fatal neonatal lacticacidemia. Am J Hum Genet 37:938-946

9. Glerum M, Yanamura W, Capaldi R, Robinson BH 1988 Characterisation of cytochrome oxidase mutants in human fibroblasts. FEBS Lett 236:100-104

10. Moreadith RW, Batshaw ML, Ohnishi $\Upsilon$, Kerr D, Knowx B, Jackson D, Hruba R, Olson J, Reynafarse B, Lehninger AL 1984 Deficiency of the iron-sulfur clusters of mitochondrial reduced nicotinamide-adenine dinucleotide-ubiquinone oxidoreductase (Complex I) in an infant with congenital lactic acidosis. J Clin Invest 74:685-697

11. DiMauro S, Nicholson JF, Hays AP, Eastwood AB, Papadimitriou A, Koeningsberger R, DeVivo DC 1983 Benign infantile mitochondrial myopathy due to reversible cytochrome c oxidase deficiency. Ann Neurol 14:226-234

12. Fischer JC, Ruitenbeek W, Stadhouders AM, Trijbels JMF, Sengers RCA, Janssen AJM, Veerkamp JH 1985 Investigation of mitochondrial metabolism in small human skeletal muscle biopsy specimens. Improvement of preparation procedure. Clin Chim Acta 145:89-94

13. MacKay ND, Robinson BH, Brodie R, Rooke-Allen N 1983 Glucose transport and metabolism in cultured human skin fibroblasts. Biochim Biophys Acta 762:198-204

14. Robinson BH, Halperin ML 1970 Transport of reduced nicotinamide adenine dinucleotide in mitochondria of rat with adipose tissue. Biochem J 116:229234

15. Krebs HA 1973 Pyridine nucleotides and rate control. Symp Soc Exp Biol 17:299-318

16. Williamson JR, Safer B, LaNoue K, Smith CM, Walajtys E 1973 Mitochondrial cytosolic interaction in cardiac tissue: role of the malate-aspartate cycle in the removal of the glycolytic NADH from the cytosol. Symp Soc Exp Biol 17:241-271

17. Ericinska M, Wilson DF 1982 Regulation of cellular energy metabolism. J Membr Biol 70:1-14

18. Sussman I, Ericinska M, Wilson DF 1980 The regulation of cellular energy metabolism. The Crabtree effect. Biochim Biophys Acta 591:209-223

19. Robinson $\mathrm{BH} 1988$ Cell cultures studies on patients with mitochondrial diseases. J Bioenerg Membranes 20:313-323

20. Glerum DM, Robinson BH, Capaldi R 1989 Fibroblasts and cytochrome c oxidase deficiency. In: Azzi A, Drahota Z, Pepa S (eds) Molecular Basis of Membrane-Associated Diseases. Springer Verlag, Berlin, pp 228-238

21. Miyabayashi S, Ito T, Abukawa D, Narisawa K, Tada K, Tanaka M, Ozawa T, Droste M, Kadenbach B 1987 Immunochemical study in three patients with cytochrome $c$ oxidase deficiency presenting Leigh's encephalomyelopathy. J Inherited Metab Dis 10:289-292

22. DiMauro S, Servidei S, Zeviani M, DiRocco M, DeVivo DC, DiDonato S, Uziel G, Berry K, Hoganson G, Johnsen S, Johnson PC 1987 Cytochrome c oxidase deficiency in Leigh syndrome. Ann Neurol 22:498-506

23. Holt IJ, Harding AE, Morgan-Hughes JA 1988 Deletions of muscle mitochondrial DNA in patients with mitochondrial myopathies. Nature 331:717-719

24. Boustany RN, Aprille JR, Halperin J, Levy H, Delong GR 1983 Mitochondrial cytochrome deficiency presenting as a myopathy with hypotonia, external ophthalmoplegia and lactic acidosis in an infant and as fatal hepatopathy in a second cousin. Ann Neurol 14:462-467

25. Sengers RCA, Trijbels JMF, Bakkeren JAJM, Ruitenbeek W, Fisher JC, Janssen AJM, Stadhouders AM, Ter Laak HJ 1984 Deficiency of cytochrome $\mathrm{b}$ and $\mathrm{aa}_{3}$ in muscle from a floppy infant with cytochrome oxidase deficiency. Eur J Pediatr 141:178-180 
26. DiMauro S, Zeviani M, Bonilla E, Bresolin N, Nakagawa M, Miranda AF, Moggio M 1985 Cytochrome c oxidase deficiency. Trans Biochem Soc 13:651-653

27. Hoppel CL, Kerr DS, Dahms B, Roessmann U 1987 Deficiency of the reduced nicotinamide adenine dinucleotide dehydrogenase component of complex 1 of mitochondrial electron transport. J Clin Invest 80:71-77

28. Pavlakis SG, Phillips PC, DiMauro S, DeVivo DC, Rowland LP 1984 Mitochondrial myopathy, encephalopathy, lactic acidosis and strokelike episodes: a distinctive clinical syndrome. Ann Neurol 16:48 I-488

29. Tanaka M, Nishikimi M, Suzuki H, Tada M, Ozawa T, Koga Y, Nonaka I 1987 Deficiency of subunits of complex I or IV in mitochondrial myopathies: immunochemical and immunohistochemical study. J Inherited Metab Dis
$10: 284-288$

30. Koga Y, Nonaka I, Kobayashi M, Tojyo M, Nihei K 1988 Findings in muscle in complex I (NADH coenzyme Q reductase) deficiency. Ann Neurol 24:749-756

31. Wallace DC, Zheng X, Loh MT, Shoffner JM, Hodge JA, Kelley RI, Epstein CM, Hopkins LC 1988 Familial mitochondrial encephalomyopathy (MERRF): genetic, patho-physiological and biochemical characterization of a mitochondrial DNA disease. Cell 55:601-616

32. Ozawa T. Yoneda M. Tanaka M, Ohno K, Sato W, Suzuki H, Nishikimi M, Yamamoto M, Nonaka I, Horai S 1988 Maternal inheritance of deleted mitochondrial DNA in a family with mitochondrial myopathy. Biochem Biophys Res Commun 154:1240-1247 